\title{
CLASSIFICAÇÃO HÍBRIDA: PIXEL A PIXEL E BASEADA EM OBJETOS PARA O MONITORAMENTO DA CONDIÇÃO DA SUPERFÍCIE DOS PAVIMENTOS RODOVIÁRIOS
}

\author{
Hybrid classification: pixel by pixel and object based to monitor the surface \\ conditions of road pavements \\ MARCOS RIBEIRO RESENDE \\ LIEDI LÉGI BARIANNI BERNUCCI \\ JOSÉ ALBERTO QUINTANILHA \\ Departamento de Engenharia de Transportes - PTR \\ Escola Politécnica da Universidade de São Paulo - EPUSP \\ marcos-resende@uol.com.br; liedi@usp.br; jaquinta@usp.br
}

\section{RESUMO}

Monitorar a condição de uso de toda a extensão das rodovias brasileiras é tarefa dispendiosa e demorada. Este trabalho trata de novas técnicas que permitem o levantamento da condição da superfície dos pavimentos rodoviários de forma ágil utilizando imagens hiperespectrais de sensor digital aeroembarcado. Nos últimos anos, um número crescente de imagens de alta resolução espacial tem surgido no mercado mundial com o aparecimento dos novos satélites e sensores aeroembarcados de sensoriamento remoto. Propõe-se uma metodologia para identificação dos pavimentos asfálticos e classificação das principais ocorrências dos defeitos na superfície do pavimento. A primeira etapa da metodologia é a identificação da superfície asfáltica na imagem, utilizando uma classificação híbrida baseada inicialmente em pixel e depois refinada por objetos. A segunda etapa da metodologia é a identificação e classificação das ocorrências dos principais defeitos nos pavimentos flexíveis que são observáveis nas imagens de alta resolução espacial. Esta última etapa faz uso intensivo das novas técnicas de classificação de imagens baseadas em objetos. O resultado final é a geração de índices da condição da superfície do pavimento a partir das imagens que possam ser comparados com os indicadores vigentes da condição da superfície do pavimento já normatizados pelos órgãos competentes no país.

Palavras-chave: Sensoriamento Remoto; Classificação de Imagens; Imagem Hiperespectral; Condição de Pavimentos; Asfalto. 
ABSTRACT

Monitoring every Brazilian road use condition is an expensive and time consuming task. This research deals with new techniques which will yield a quick survey of road surface pavement condition by using hyperspectral images from airborne remote sensing. Recently, an increasing number of images with high spatial resolution has emerged on the world market with the advent of new remote sensing satellites and airborne sensors. Hyperspectral images from digital airborne sensor have been used in this work. A new identification methodology for a pavement surface and also for classification of the main defects of the surface has been devised. The first step of the methodology is the identification of the asphalt surface in the image, by using hybrid classification based on pixel initially and then improved by objects. The second step of the methodology is the identification and classification of the main defects of pavement surface that are observable in high spatial resolution imagery. This step makes intensive use of new techniques for classification of images based on objects. The goal is the generation of pavement surface condition index from the images which can be compared to quality index of pavement surface already managed by the regulatory agency in the country.

Keywords: Remote Sensing; Image Classification; Hyperspectral Image; Pavement Condition; Asphalt.

\section{INTRODUÇÃO}

A Agência Nacional de Transportes Terrestres (ANTT) em seu Anuário Estatístico dos Transportes Terrestres - AETT (2008) afirma que o Brasil, em todo o seu território, possui $211.678 \mathrm{~km}$ de rodovias pavimentadas, sendo $61.304 \mathrm{~km}$ de rodovias federais, $17.056 \mathrm{~km}$ de rodovias estaduais coincidentes, $106.548 \mathrm{~km}$ de rodovias estaduais e $26.770 \mathrm{~km}$ de rodovias municipais.

Segundo a pesquisa rodoviária CNT (2009), “o levantamento realizado pela pesquisa em $89.552 \mathrm{~km}$ da malha rodoviária do País, em 43,4\% (38.870 km) a condição da superfície de rolamento é, predominantemente, perfeita. Por sua vez, em 33,1 \% o pavimento apresenta sinais de desgaste e, em 23,5 \% predominam defeitos, principalmente trincamentos e/ou remendos (17,8\%) e afundamentos, ondulações e buracos (4,6\%). A situação denominada de "crítica", onde o pavimento está totalmente destruído, é predominante em 1,1\%, ou seja, 960 km”. Vale lembrar que a pesquisa da CNT cobre uma extensão apreciável, porém não atinge 50\% da malha rodoviária. A extensão não pesquisada apresenta vários problemas de condição de superfície e, às vezes, estas estradas são de difícil acesso.

$\mathrm{O}$ avanço na tecnologia de sensoriamento remoto tem demonstrado capacidade em detectar propriedades físicas e químicas dos materiais em escalas e condições que permitem utilizá-las para o monitoramento das condições dos pavimentos rodoviários. O objetivo deste artigo é apresentar a investigação realizada na utilização de imagens digitais, obtidas por sensores aerotransportados, de alta resolução espacial e espectral, no monitoramento da condição de uso dos 
pavimentos. Para tanto, foi criada uma metodologia de processamento e análise das imagens para extrair os índices da condição dos pavimentos, normalmente utilizados em trabalhos desse tipo, diretamente das imagens coletadas. A descrição detalhada da metodologia desenvolvida para determinar quais defeitos da superfície dos pavimentos são detectados pelas imagens disponíveis e como são gerados os índices da condição da superfície do pavimento a partir dessas imagens e sua comparação com os índices já normatizados pelos órgãos competentes do país, constam de Resende et al. (2011).

O presente artigo está organizado do seguinte modo: a Seção 2 traz um resumo da bibliografia sobre índices e métodos de levantamento da condição de pavimentos e classificação de imagens; na Seção 3 se discorre sobre os dados utilizados e a área de estudo; na Seção 4 é apresentada a metodologia e as observações realizadas em campo para confirmar as observações feitas nas imagens; as seções 5, 6 e 7 trazem, respectivamente, os resultados, uma discussão desses resultados e as conclusões do artigo.

\section{REVISÃO BIBLIOGRÁFICA}

Os principais métodos vigentes no Brasil para avaliação da condição da superfície dos pavimentos asfálticos e geração de índices de qualidade atuais são os estabelecidos pelas normas DNIT 006/2003 - PRO e DNIT 008/2003 - PRO. A norma DNIT 006/2003 - PRO estabelece um método de levantamento sistemático de defeitos e atribuição do Índice de Gravidade Global (IGG). O IGG é um indicador da condição da superfície do pavimento. A partir do número calculado do IGG é possível conferir ao pavimento inventariado um conceito que retrata o grau de degradação atingido pela superfície do pavimento em: ótimo, bom, regular, ruim e péssimo. A norma DNIT 008/2003 - PRO fixa as condições exigíveis na avaliação da superfície de pavimentos flexíveis e semirrígidos pelo processo de Levantamento Visual Contínuo (LVC) determinando-se o Índice de Condição de Pavimentos Flexíveis (ICPF), ao mesmo tempo em que proporciona também os elementos necessários para o cálculo do Índice de Gravidade Global Expedito (IGGE). O IGGE é calculado através da frequência dos defeitos e seus respectivos pesos. Os defeitos são agrupados em três conjuntos: trincas, deformações e panelas (buracos)/remendos.

A busca por métodos de levantamento da condição dos pavimentos que permitam a melhoria e a sistematização dos métodos manuais tradicionais é recorrente. O uso de vídeo e imagens torna-se um instrumento valioso para alcançar tal objetivo. Desde 1982, estudos do Departamento de Engenharia Civil da Universidade de Waterloo, USA, propõem a utilização de um sistema especialista para automação do levantamento de dados da condição dos pavimentos (HAAS et al., 1995) por meio de câmeras de vídeo montadas em veículos, onde a posteriori, as imagens são digitalizadas, processadas e classificadas. Fukuhara et al. (1990) propôs um sistema de levantamento da condição dos pavimentos automático que utiliza laser, vídeo e técnicas de processamento de imagens também sobre veículo 
terrestre, capaz de detectar e calcular diferentes parâmetros, tais como: comprimento, largura, direção, posição e número de trincas. De acordo com Wang e Smadi (2011), a implementação bem sucedida do sistema laser 3D de aquisição de dados aumenta as esperanças entre os pesquisadores de que a melhor solução para o processamento automático de defeitos superficiais de pavimentos pode estar perto. No entanto, segundo os mesmos autores, a detecção e classificação de trincas em campo ainda não foram totalmente automatizadas. Uma quantidade substancial de intervenção manual pós-processamento ainda é necessária. Atualmente, a maioria dos sistemas de levantamento da condição dos pavimentos é sobre veículos terrestres equipados com diferentes tipos de sensores. Outra forma de levantamento de informações sobre a condição dos pavimentos que está em desenvolvimento são as plataformas aéreas que podem ser aeronaves pilotadas ou veículos aéreos remotamente pilotados. Segundo Herold et al. (2008), o National Center for Remote Sensing in Transportation (NCRST) na Universidade da Califórnia de Santa Bárbara vem utilizando imagens espectrais de sensoriamento remoto no mapeamento urbano e infraestrutura das rodovias. Utilizam imagens do sensor Airborne Visible/Infrared Imaging Spectrometer (AVIRIS) para determinação da idade e condição do pavimento e também para determinação da linha central de rodovias. No Brasil, Resende et al. (2008) utilizaram imagens de alta resolução espacial e espectral de plataformas aéreas para extração de rodovias asfaltadas. Ferreira e Vieira (2009 a, b) realizaram experimentos com imagens de satélites de alta resolução para a detecção de defeitos nas superfícies dos pavimentos asfálticos utilizando técnicas de reconhecimento de padrões e para tentar discriminar a faixa do espectro eletromagnético que melhor diferencie os padrões de asfalto via espectroradiômetros. Esses autores concluíram, à época, que o uso de imagens do sensoriamento remoto de altíssima resolução para o inventário do estado da superfície de estradas pavimentadas, apresenta grande dificuldade para detectar defeitos, principalmente devido à resolução espacial dos sensores disponíveis e que um sistema sensor (neste caso, terrestre) que opere basicamente na faixa do visível, atenderia sem maiores problemas ao objetivo de se detectar trincas.

As principais técnicas de classificação de imagens baseiam-se na abordagem pixel a pixel, onde cada pixel da imagem é comparado com determinadas classes de interesse. Dentre estas técnicas, o "SAM (Spectral Angle Mapper) é uma ferramenta que permite um mapeamento rápido da semelhança espectral do espectro da imagem com o espectro de referência” (BOARDMAN, 1993). Os espectros de referência podem ser tanto de laboratório ou de campo, ou extraídos a partir da imagem em análise. Segundo Lillesand, Kiefer e Chipman (2007), para comparar dois espectros, como o espectro de um pixel da imagem com o espectro de uma biblioteca espectral, os vetores são definidos no espaço multidimensional ${ }^{1}$ e o ângulo entre os vetores calculado. Os autores completam que se o ângulo é menor que um nível de tolerância, os espectros são considerados iguais, mesmo que um espectro seja mais

\footnotetext{
${ }^{1}$ Espaço de atributos (feature space)

Bol. Ciênc. Geod., sec. Artigos, Curitiba, v. 18, nº 3, p.397-420, jul-set, 2012.
} 
brilhante do que o outro. A técnica de classificação de imagens pixel a pixel tem desvantagens em imagens de alta resolução espacial. Essa desvantagem muitas vezes é traduzida no efeito conhecido como "Sal e Pimenta". Segundo (BLASCHKE; LANG; HAY, 2008), este efeito acontece quando o pixel não é maior ou igual aos objetos pesquisados e a área de interesse possui grande heterogeneidade como no caso dos cenários urbanos. A classificação resultante é também uma imagem com grande heterogeneidade. Análise de imagens implica lidar com a semântica da imagem, segundo Baatz e Schape (2000). Os autores discutem que na maioria dos casos a informação semântica, importante para entender uma imagem, não está representada em pixels individuais, mas em objetos de imagem significativos e suas relações mútuas. Dentro deste contexto, um novo termo vem sendo cunhado na última década na comunidade internacional de sensoriamento remoto para lidar com a técnica de Análise de Imagens Baseada em Objetos (OBIA). O principal propósito da OBIA, no contexto do sensoriamento remoto, é fornecer métodos adequados e automatizados para a análise de imagens de alta resolução espacial (VHSR) descrevendo a realidade da imagem usando as características espectral, textura, espacial e topológica, conforme discutido por Lang (2008). OBIA surgiu como uma alternativa ao paradigma tradicional baseado em pixel e é baseado na ideia de que, deslocando as unidades básicas de pixels para objetos de imagem, pode-se emular (ou exceder) a interpretação visual, fazer melhor utilização da informação espacial implícita nas imagens de sensoriamento remoto, e, ao mesmo tempo, proporcionar uma maior integração com os vetores dos sistemas de informações geográficas (HAY; CASTILLA, 2008). Segundo Pinheiro e Kux (2005), a análise baseada em objeto tem como princípio dois passos: (i) segmentação/multiresolução, e (ii) classificação. No primeiro, são criados objetos em diferentes escalas (segmentação em diferentes níveis), conectados entre si, de acordo com critérios de forma e cor. No segundo passo, os objetos passam a se relacionar através da definição da rede hierárquica (herança dos atributos que descrevem a classe) e da rede semântica (estrutura lógica de relação entre as classes). Para a classificação é utilizado o maior grau de pertinência dos objetos à determinada classe por meio da lógica fuzzy. A segmentação é a base da classificação por objetos. É a partir da segmentação que as informações intrínsecas do objeto de forma e de textura são calculadas, e também a construção dos relacionamentos com os outros objetos é construída.

\section{DADOS E ÁREA DE ESTUDO}

O conjunto de dados utilizado nesta pesquisa é formado por quatro imagens do sensor CASI-1500 adquiridas pela plataforma do Sistema de Monitoramento Aéreo de Baixo Custo (SMABC) (RODRIGUES, 2007), datadas de 03 de fevereiro de 2010. As imagens geradas pelo sensor CASI-1500 para este estudo são todas do espectro visível e infravermelho próximo. Duas imagens (Imagens 1 e 2, respectivamente) com 24 bandas espectrais contínuas de 380,1 nm até 1.033,1 nm, resolução espacial de $50 \mathrm{~cm}$ por pixel e 14 bits de resolução radiométrica e mais 
duas imagens (Imagens 3 e 4) com 8 bandas espectrais contínuas de 380,1 nm até $1.004,8 \mathrm{~nm}$, resolução espacial de $25 \mathrm{~cm}$ por pixel e 14 bits de resolução radiométrica, conforme mostra a Tabela 1.

Tabela 1 - Descrição das bandas espectrais das imagens utilizadas na pesquisa.

\begin{tabular}{lll}
\hline Banda & $\begin{array}{l}\text { Imagem 01-I01 }(\mathrm{nm}) \\
\text { Imagem 02-I02 }(\mathrm{nm})\end{array}$ & $\begin{array}{l}\text { Imagem 03-I03 }(\mathrm{nm}) \\
\text { Imagem 04-I04 }(\mathrm{nm})\end{array}$ \\
\hline B01 & $380.1+/-14.1$ & $408.4+/-42.4$ \\
B02 & $408.3+/-14.1$ & $493.4+/-42.5$ \\
B03 & $436.7+/-14.2$ & $578.5+/-42.6$ \\
B04 & $465.0+/-14.2$ & $663.8+/-42.7$ \\
B05 & $493.3+/-14.2$ & $749.1+/-42.7$ \\
B06 & $521.7+/-14.2$ & $834.5+/-42.6$ \\
B07 & $550.1+/-14.2$ & $919.7+/-42.6$ \\
B08 & $578.5+/-14.2$ & $1004.8+/-42.5$ \\
B09 & $606.9+/-14.2$ & \\
B10 & $635.4+/-14.2$ & \\
B11 & $663.8+/-14.2$ & \\
B12 & $692.3+/-14.2$ & \\
B13 & $720.7+/-14.2$ & \\
B14 & $749.1+/-14.2$ & \\
B15 & $777.6+/-14.2$ & \\
B16 & $806.0+/-14.2$ & \\
B17 & $834.5+/-14.2$ & \\
B18 & $862.9+/-14.2$ & \\
B19 & $891.3+/-14.2$ & \\
B20 & $919.7+/-14.2$ & \\
B21 & $948.1+/-14.2$ & \\
B22 & $976.4+/-14.2$ & \\
B23 & $1004.8+/-14.2$ & \\
B24 & $1033.1+/-14.2$ & \\
\hline
\end{tabular}

Imagens com múltiplas faixas (bandas) do espectro eletromagnético, como as utilizadas (24 bandas nas duas primeiras imagens e 8 nas duas últimas), são ditas imagens hiperespectrais. $O$ fato de todas elas terem uma resolução espacial submétrica, as caracteriza como de alta resolução espacial. No desenvolvimento deste trabalho, todas as bandas pertencentes às respectivas imagens foram utilizadas durante as etapas de processamento; não houve pré-seleção de bandas e todas as bandas participaram da classificação com o mesmo peso.

A área de estudo, mostrada na Figura 1, está localizada na região urbana do município de Sorocaba, cortada pela Rodovia Raposo Tavares, SP-270, dentro do

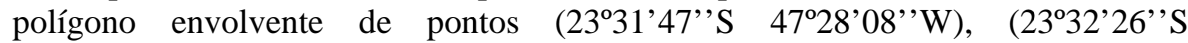
Bol. Ciênc. Geod., sec. Artigos, Curitiba, v. 18, nº 3, p.397-420, jul-set, 2012. 


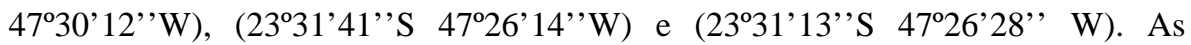
imagens foram capturadas em uma janela de oportunidade de um voo já programado para o SMABC. Desta forma, não foi possível sobrevoar uma região onde houvesse um número maior de ocorrências de defeitos da superfície do pavimento asfáltico. Nesse sentido, a metodologia aqui proposta ganha significado maior, uma vez que a realidade nacional do estado de nossas rodovias é bem diferente desta, apresentando em geral pior condição de pavimento. Trabalhos práticos de aplicação da metodologia podem ajudar tanto na identificação de prioridades quanto na avalição posterior das possíveis causas dessas ocorrências para melhor diagnosticar os problemas e projetar as soluções.

Figura 1 - Composição colorida RGB das I01B10 (R), I01B07 (G) e I01B04 (B), correspondentes a 635,4nm, 550,1nm e 465,0 nm) da imagem I01 com 24 bandas espectrais e $50 \mathrm{~cm}$ resolução espacial da Área de Estudo, Sorocaba, São Paulo - SP

(Atech, 2010).

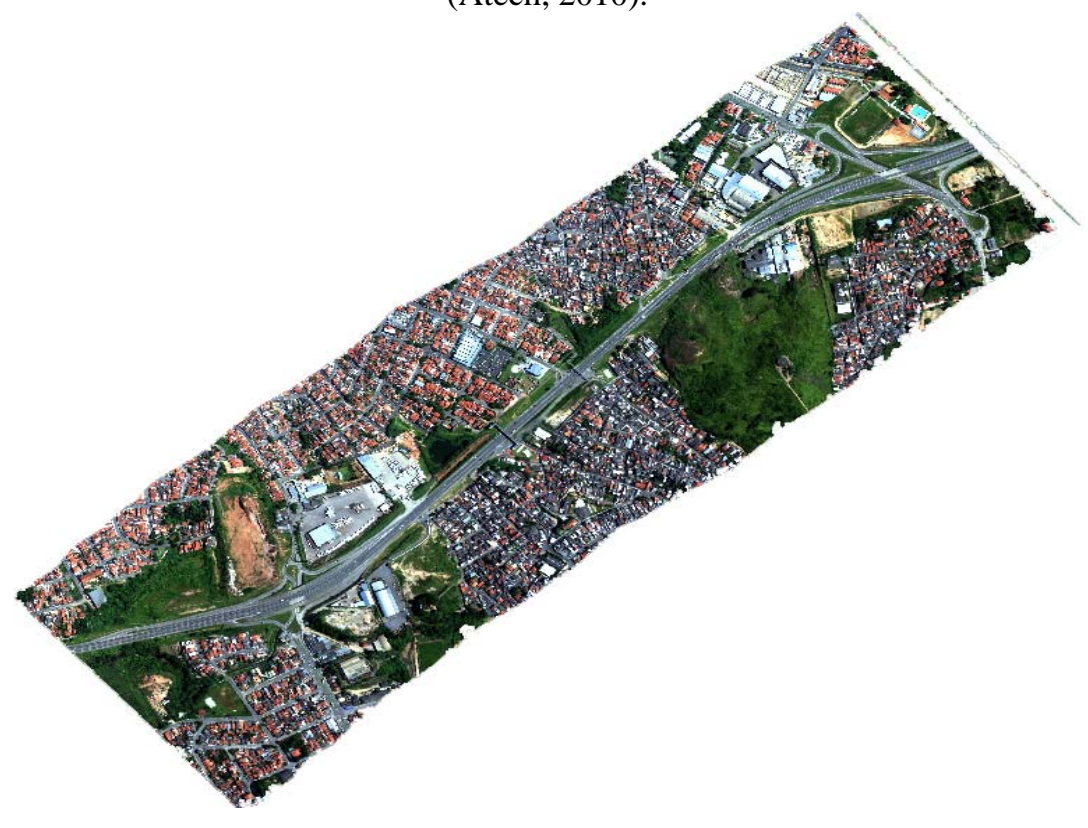

\section{METODOLOGIA}

A utilização de imagens hiperespectrais e com alta resolução espacial no monitoramento da condição da superfície dos pavimentos asfálticos requer um conjunto de etapas de processamento e adequação das informações de entrada para produção dos resultados esperados. A partir de uma imagem hiperespectral, o objetivo é criar índices que permitam mensurar a condição da superfície dos pavimentos rodoviários. A metodologia tem como base dois processos principais: (i) 
detecção de vias asfaltadas, e (ii) classificação dos defeitos do pavimento asfáltico. A Figura 2 mostra a metodologia utilizada, descrita a seguir.

Figura 2 - Fluxograma com as etapas da metodologia geral proposta.

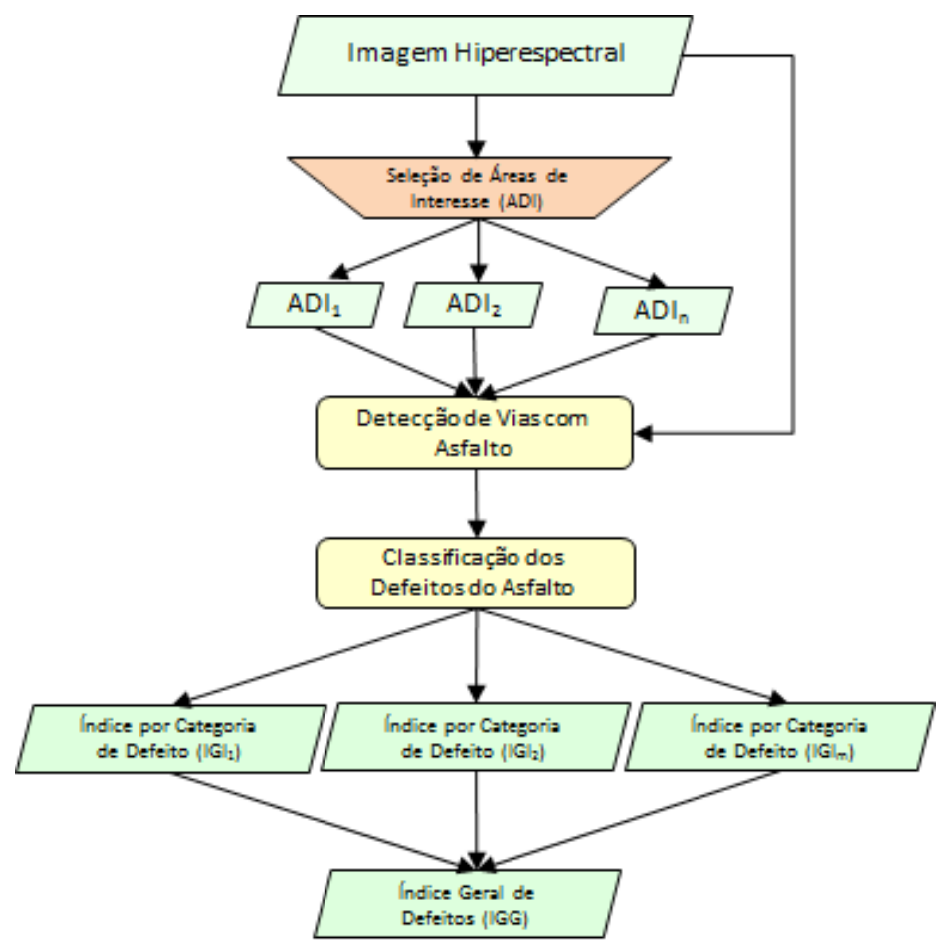

Para minimizar o esforço computacional necessário nas etapas de estudo e validação da metodologia, foram escolhidas Área De Interesse (ADI) que fossem representativas de todo o conjunto e que possuíssem defeitos nos pavimentos passíveis de identificação nas imagens disponíveis. A seleção das áreas de interesse foi feita a partir da análise visual com o objetivo de selecionar áreas significativas obedecendo aos seguintes critérios, criados de forma a cobrir todos os fatores existentes:

a. Tipo de ocupação:

i. Área com características evidentemente urbanas;

ii. Área com características evidentemente rurais;

b. Resolução espectral do sensor:

i. Área coberta por imagem de 8 bandas espectrais;

ii. Área coberta por imagem com 24 bandas espectrais;

c. Resolução espacial decorrente da cobertura disponibilizada: 
i. Área com resolução espacial de 25 cm;

ii. Área com resolução espacial de $50 \mathrm{~cm}$;

d. Áreas com as menores interferências da operação do sensor (menos ruídos ou defeitos de imagens provocados pelo sensor);

e. Áreas com defeitos do pavimento asfáltico que foram posteriormente identificadas em função da pesquisa de campo.

\subsection{Processo 1: Detecção de Vias com Asfalto}

Para realizar a classificação e a identificação dos defeitos do pavimento, o primeiro passo é distinguir na imagem original o que é superfície asfáltica. Este passo, por si só, já é um grande trabalho dentro da área de sensoriamento remoto e tratamento de imagens, principalmente, quando as imagens são de áreas urbanas. Imagens de área urbana, adquiridas em alta resolução, apresentam grande heterogeneidade. Com o objetivo de identificar as superfícies asfálticas nas imagens hiperespectrais de alta resolução espacial, a metodologia ilustrada na Figura 3 foi aplicada. Esta metodologia combina a técnica de classificação por pixel, onde a natureza da resposta espectral dos alvos é considerada, com a técnica de classificação baseada em objetos, que além das informações espectrais leva em consideração os aspectos espaciais e a morfologia dos objetos que estão em análise. Outros detalhes sobre classificação baseada em objetos pode ser obtida em Navulur (2006) e sobre a particular técnica adotada neste trabalho em Nóbrega et. al. (2008).

Figura 3 - Processo para a detecção e separação do asfalto em imagens hiperespectrais.

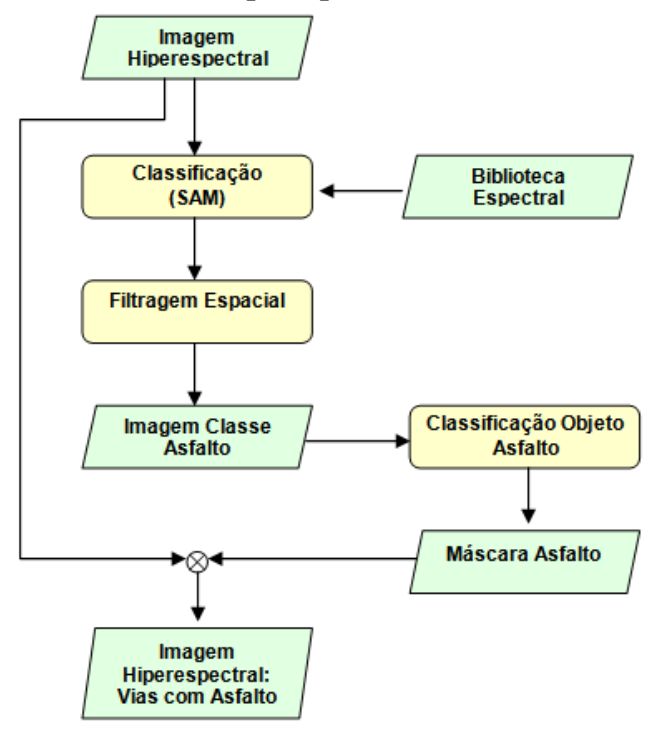

Bol. Ciênc. Geod., sec. Artigos, Curitiba, v. 18, nº 3, p.397-420, jul-set, 2012. 
Na primeira fase da detecção do pavimento asfáltico é feita a classificação supervisionada da imagem utilizando-se o algoritmo SAM. O algoritmo determina a similaridade espectral entre dois espectros pelo cálculo do ângulo entre os dois, tratando-os como vetores em um espaço com dimensionalidade igual ao número de bandas da imagem (KRUSE et al., 1993). Sendo o SAM um algoritmo de classificação supervisionada, necessita de referências ou amostras para que a classificação seja realizada. Uma forma de fornecer os padrões espectrais de referência é através de uma biblioteca espectral. A biblioteca da Figura 4 foi criada a partir das próprias imagens e descreve o comportamento espectral de diferentes tipos de asfalto encontrados nas imagens (Figura 4, pontos a, b, c, d, e, f, g e h). Em especial nesta subseção, o foco do trabalho não foi na seleção das melhores bandas espectrais para detecção dos pavimentos asfálticos e sim na classificação dos pavimentos. O número maior de bandas, resolução espectral, aumenta o poder discriminatório do classificador, permitindo que a curva espectral do alvo de interesse seja melhor caracterizada.

Figura 4 - Pontos de amostras nas imagens I01 e I02, e, no gráfico, as curvas espectrais dos respectivos pontos amostrados que compõem a biblioteca espectral.
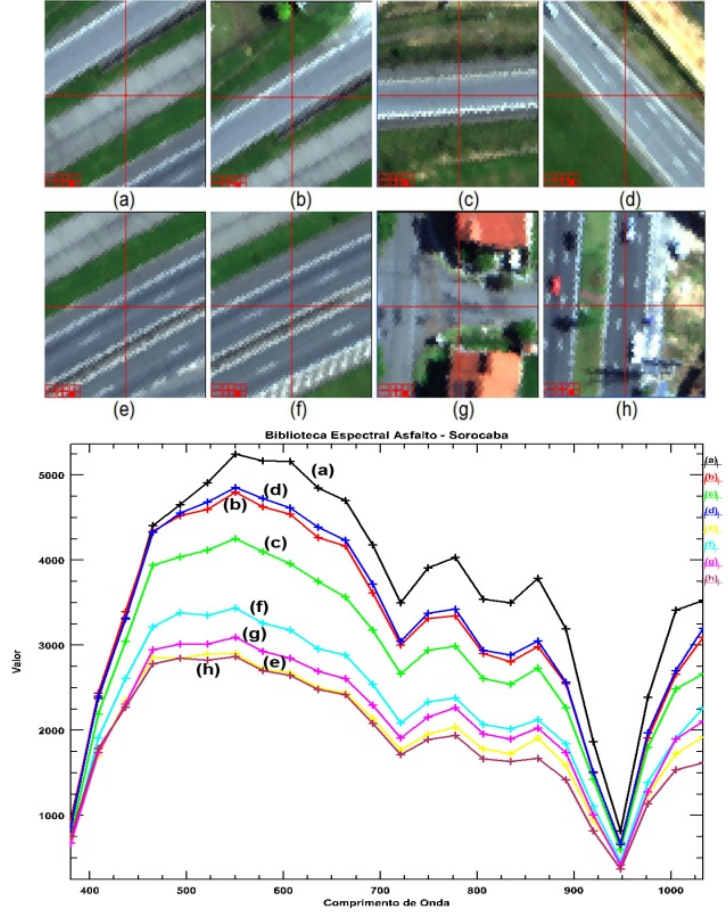

Bol. Ciênc. Geod., sec. Artigos, Curitiba, v. 18, nº 3, p.397-420, jul-set, 2012. 
A segunda fase do processo de detecção é composta de filtros espaciais que são aplicados às imagens com objetivo de melhor a classificação. O filtro de Clump é utilizado para aglutinar áreas adjacentes que possuem classificação similar, sem permitir a contaminação pelos códigos de outras classes (ENVI, 2001). O filtro de convolução da média tende a suavizar a imagem, principalmente as bordas dos objetos, ajuda a remover a ocorrência de pixels isolados. A primeira e a segunda fase de processamento foram realizadas no software ENVI 4.2.

A terceira fase do processo de detecção do pavimento asfáltico tem como objetivo remover os objetos da imagem que foram classificados erroneamente na etapa anterior. Com a classificação baseada em objetos é possível fazer a análise espacial dos objetos, ou seja, estudar a vizinhança de objeto detectado como superfície asfáltica e verificar se essa vizinhança também se constitui de revestimento asfáltico, uma vez que o objeto "asfalto", em rodovias e ruas como é o caso, não se constitui de áreas isoladas ou não adjacentes. Objetos isolados na imagem classificada não devem ser tratados como "asfalto".

Para esta fase foi utilizado o software Definiens 7 que realiza a classificação baseada em objeto. Para remoção dos objetos isolados na imagem que não são pavimento asfáltico, foram criadas três classes: (i) "Asfalto” (que representa as vias asfaltadas), (ii) "NãoÉAsfalto" (que representa outros objetos identificados e que não são vias asfaltadas), (iii) e "IlhaAsfalto", que compreende as regiões isoladas classificadas como pavimento asfáltico. A classe "Asfalto" foi definida pelo valor espectral e com a condição de não pertencer a classe "IlhaAsfalto". A classe "NãoÉAsfalto" foi definida somente pelo valor espectral. A classe "IlhaAsfalto" foi definida pelos critérios de vizinhança. O objeto para ser da classe "IlhaAsfalto" deve inicialmente possuir os mesmos valores espectrais da classe "Asfalto" e ser cercada pela classe "NãoÉAsfalto”. Após o término da classificação, os objetos das classes "IlhaAsfalto" e "NãoÉAsfalto" são descartados, mantendo-se somente os objetos da classe “Asfalto”. A Figura 5 mostra a definição das classes citadas acima no software Definiens 7.

Figura 5 - Definição das classes Asfalto, IlhaAsfalto e NãoÉAsfalto no software Definiens 7.

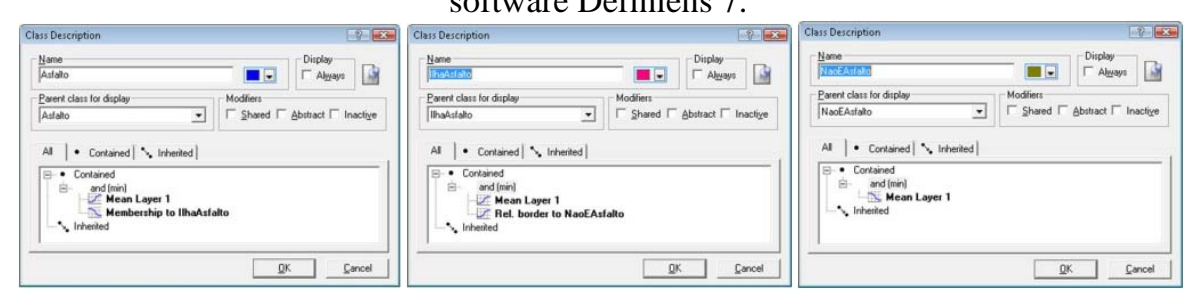

A partir do resultado da classificação baseada em objeto asfalto, Figura 3, é realizada uma transformação na imagem para geração de uma máscara binária. A máscara é aplicada na imagem hiperespectral original recortando as vias com 
asfalto. Ao final tem-se uma imagem hiperespectral recortada contendo somente asfalto.

\subsection{Processo 2: Classificação dos Defeitos do Asfalto}

Esta etapa de classificação baseia-se prioritariamente na geometria dos objetos utilizando as ferramentas e medidas disponíveis no software de análise baseado em objeto, procurando encontrar os padrões existentes nos defeitos do pavimento asfáltico. Neste trabalho foram investigadas as ocorrências de remendos, panelas (ou buracos) e as trincas longas. Os remendos e as trincas longas foram os defeitos de maior ocorrência. Nas imagens trabalhadas houve somente uma ocorrência de panela/buraco, o que impossibilitou a aplicação da metodologia nesta categoria de defeito. Em função da resolução das imagens adquiridas e a ausência de informação de profundidade nas imagens, os outros defeitos do pavimento asfáltico não foram investigados, tais como: afundamentos, corrugação e escorregamento.

A Figura 6 mostra essa parte da metodologia. No caso, o material de entrada (Imagem Hiperespectral: Vias com Asfalto) são as imagens do Processo 1 que serão novamente segmentadas e classificadas em função de cada tipo de defeito do pavimento. A segunda etapa da metodologia (processo de classificação dos defeitos do asfalto) é muito mais susceptível à qualidade das amostras (ruídos, distorções, resolução, etc) do que a primeira etapa de deteç̧ão do pavimento Asfáltico, pois a dimensão dos objetos de interesse são, na maioria, menores do que a resolução espacial das imagens disponíveis. Os remendos são os defeitos com o maior número de ocorrências nas imagens disponíveis e também são os de maior visibilidade em função do tamanho dos objetos versus a resolução das imagens. Para a classificação dos remendos do pavimento asfáltico nas imagens pesquisadas foi construída uma classe que considera tanto os aspectos espectrais quantos os aspectos de forma dos objetos. Os seguintes atributos de forma foram utilizados na classe remendo: Índice de borda (Border Index), Relação Comprimento Largura (Lenght/Width), Ajuste Retangular (Retangular Fit) e o Índice de Forma (Shape Index). Para a construção das funções de pertinência dos atributos da classe, foram coletadas amostras de objetos "remendo" na própria imagem. Os valores das amostras para os atributos que compõem a classe "remendo", descritos acima, serviram para dimensionar o intervalo de confiança das funções de pertinência. Na ausência de outras imagens com resolução espacial melhor e com mais informações e amostras de outros tipos de trincas, as imagens disponíveis foram processadas e trabalhadas buscando-se o aprimoramento da metodologia e o entendimento do comportamento dos objetos que ilustram esta classe. Por serem alvos menores do que a resolução espacial das imagens, as trincas possuem um comportamento peculiar quando comparado a outros objetos da cena, mesmo considerando as trincas que foram alargadas por selante. A classe TrincaLonga foi definida a partir dos seguintes atributos: Área, relação Comprimento Largura, Índice de Forma e os valores espectrais. A classe foi construída tendo como base o comportamento delgado dos objetos, o que justifica a utilização da relação Comprimento Largura e do Índice de Forma e, também, por 
apresentar em tese área de valores pequenos. Para a construção das funções de pertinência dos atributos selecionados para classe TrincaLonga foram utilizadas amostras de trincas das áreas de interesse. O último passo do processamento da Classificação dos Defeitos do Asfalto é a geração dos índices por defeito encontrados nas imagens semelhantes ao Índice de Gravidade Individual (IGI) e, consequentemente, a geração do índice global semelhante ao Índice Gravidade Global (IGG) ambos da norma DNIT 006/2003 ou do Índice Gravidade Global Expedito (IGGE) da norma DNIT 008/2003. Todo o processamento das imagens para esta etapa da metodologia foi realizado no software Definiens 7.

Figura 6 - Processo para a classificação dos defeitos do asfalto.

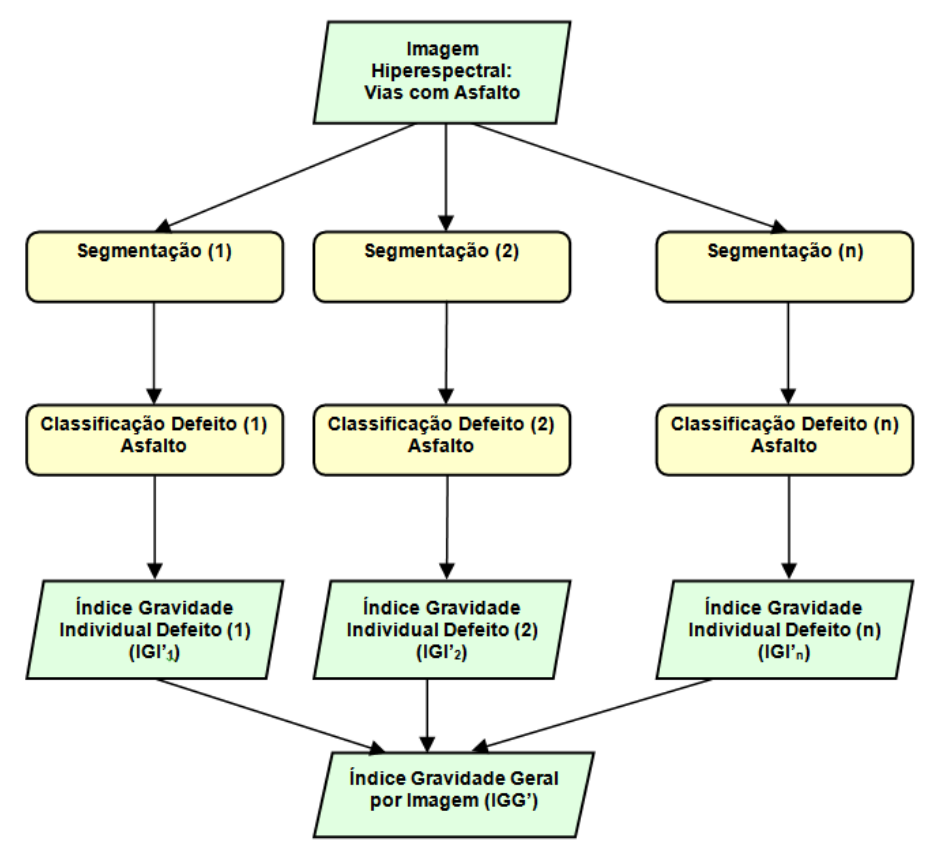

Este trabalho propõe a Equação 1 para descrever o Índice de Gravidade Individual obtido por imagem (IGI'). O IGG' é calculado para as categorias de defeito do asfalto e é obtido pela razão da soma das áreas de cada objeto classificado como pertencente ao defeito, dividido pela soma das áreas dos objetos classificados como asfalto na imagem que está sendo analisada. 


$$
I G I_{\text {Cat }}^{\prime}=\frac{\sum_{i=1}^{n} \text { área }\left(\mathrm{ObjCat}_{i}\right)}{\sum_{j=1}^{l} \text { área }\left(\mathrm{ObjAsf}_{j}\right)}
$$

Onde para uma dada imagem ou área de interesse:

IGI' $_{\text {Cat }}=$ Índice de Gravidade Individual de uma categoria de defeitos (e.g.: remendo, trinca, buraco, etc);

ObjCat = Objetos classificados como sendo da categoria de defeitos em análise;

ObjAsf = Objetos classificados como asfalto;

área() = função que retorna a área de um objeto da imagem.

Este trabalho propõe também a Equação 2 para descrever o Índice de Gravidade Global por imagem (IGG') da superfície dos pavimentos e é obtido pela soma ponderada dos índices gravidade individual de cada categoria de defeito (IGI'Cat).

$$
I G G^{\prime}=\sum_{C a t=1}^{n} k_{c a t} \times I G I_{c a t}^{\prime}
$$

Onde:

IGG' = representa o índice gravidade global de defeito para uma dada imagem ou área de interesse;

Cat = representa a categoria do defeito: remendo, trinca, buraco, etc;

$\mathrm{K}$ = representa a um fator de ponderação de cada categoria de defeito na composição do índice geral. Esse valor K é estabelecido pelas normas do DNIT.

\subsection{Pesquisa de Campo}

Com objetivo de confirmar em campo as ocorrências de alguns problemas identificados nas imagens, tais como remendos e trincas transversais longas, foi realizada uma pesquisa de campo nos locais das áreas de interesse. A pesquisa de campo foi realizada aproximadamente um mês após o voo de aquisição das imagens, de tal forma que as cenas não sofreram alterações significativas.

Após esse levantamento, dois aspectos importantes da análise foram claramente identificados:

1) As panelas ou buracos mostrados na Figura 7c não haviam sido detectados somente a partir da análise das imagens. A partir dos dados coletados em campo foi possível localizar visualmente nas imagens as ocorrências dos buracos encontrados no asfalto. A justificativa é que a dimensão dos buracos é de aproximadamente $50 \mathrm{~cm}$ de diâmetro. Na imagem com melhor resolução espacial $(25 \mathrm{~cm})$, o buraco equivale aproximadamente a 4 pixels, inviabilizando, praticamente, a detecção pelos algoritmos de classificação. 
2) Da análise visual preliminar das imagens em laboratório, um conjunto de trincas transversais longas foi identificado nas imagens, como mostrado na Figura 8a. No entanto, durante a pesquisa de campo contatou-se que a maioria destas trincas transversais longas haviam sido seladas com material impermeabilizante asfáltico de cor negra (Figuras 8b e 8c). O material selante aumentou o contraste e a área aparente das trincas, destacando-as nas imagens capturadas.

Figura 7 - (a) ADI-02 e pontos de coleta das imagens; (b), (c) e (d) imagens da pesquisa de campo.
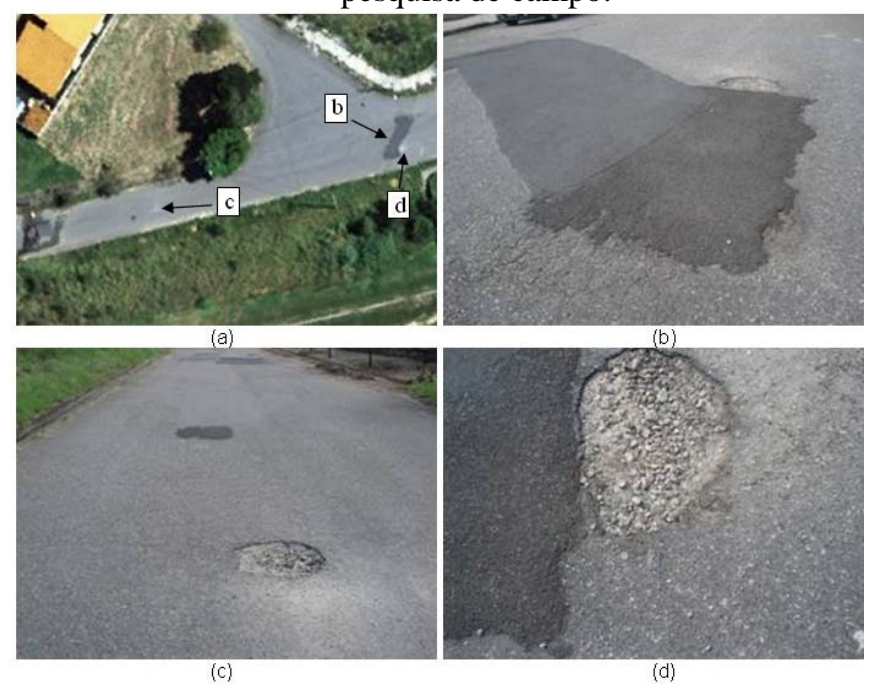

Figura 8 - (a) Pontos de coleta das imagens; (b) e (c) imagens da pesquisa de campo.

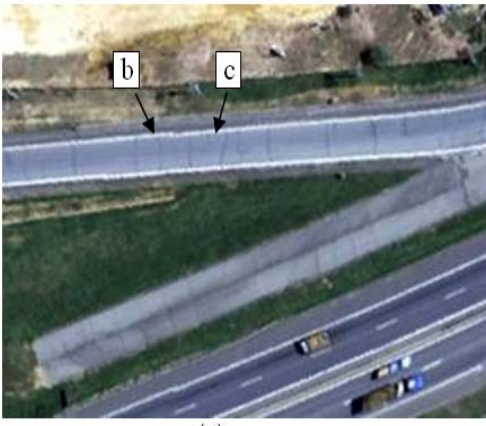

(a)

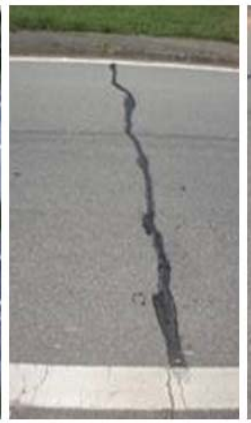

(b)

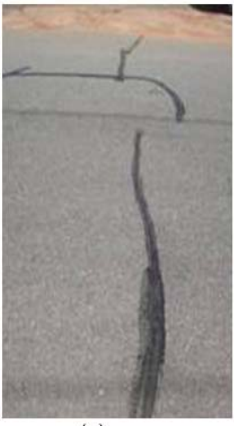

(c)

Bol. Ciênc. Geod., sec. Artigos, Curitiba, v. 18, nº 3, p.397-420, jul-set, 2012. 


\section{RESULTADOS}

A imagem da Figura 9 é o resultado da fase de classificação por objetos do processo de detecção do asfalto. Em azul os objetos da classe "Asfalto", em vermelho os objetos da classe "IlhaAsfalto" e em marrom os objetos da classe "NãoÉAsfalto".

Para avaliar o resultado do processamento da primeira etapa da metodologia, foram construídas manual e visualmente imagens de verdade de campo para as áreas de interesse mencionadas. Com essas imagens, foi possível calcular a matriz de confusão do resultado do processamento e assim avaliar a exatidão dos passos da metodologia.

Figura 9 - Resultado do algoritmo de classificação baseada em objetos da última fase do processo detecção de vias asfaltadas.

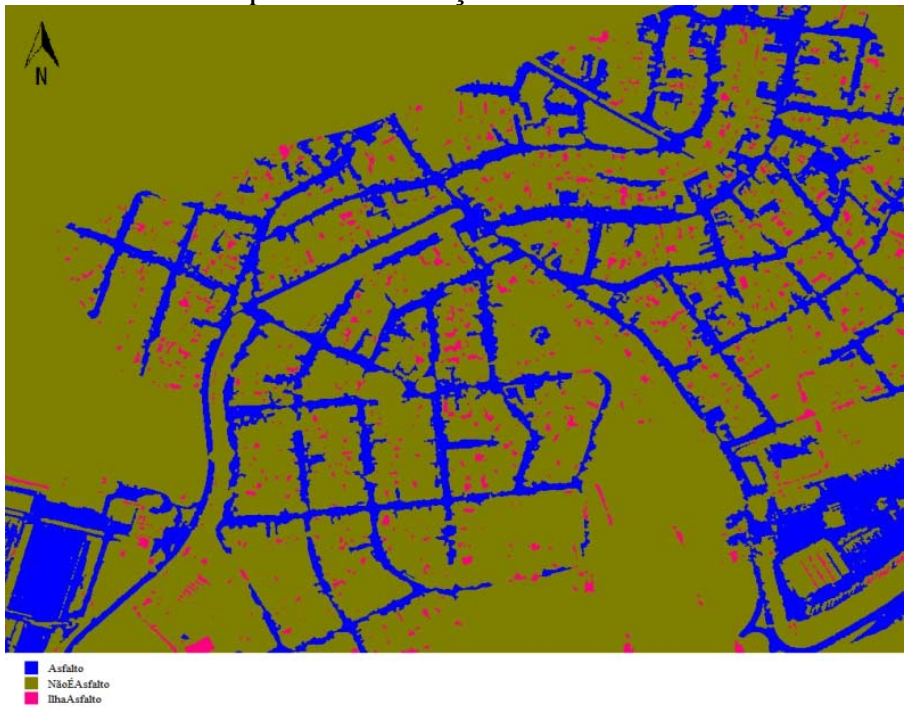

A Tabela 2 sintetiza o resultado final do processo de detecção das vias asfaltadas para as ADI pesquisadas. A coluna Exatidão SAM é a exatidão após a classificação pixel a pixel utilizando o classificador SAM, a coluna Exatidão Filtros Espaciais é a exatidão após a aplicação dos filtros espaciais na imagem classificada e a coluna Exatidão Classificação Objetos é a exatidão após a classificação por objetos para retiradas de ilhas de asfalto. A Figura 10 mostra as imagens da ADI-01 processadas na detecção das vias asfaltadas. 
Tabela 2 - Avaliação da exatidão da classificação SAM, após aplicação dos filtros espaciais e após a classificação por objetos nas ADI.

\begin{tabular}{c|c|c|c}
\hline Área de Interesse & Exatidão SAM & $\begin{array}{c}\text { Exatidão Filtros } \\
\text { Espaciais }\end{array}$ & $\begin{array}{c}\text { Exatidão } \\
\text { Classificação Objeto }\end{array}$ \\
\hline ADI 01 & 91,22 & 92,51 & 93,06 \\
\hline ADI 02 & 95,03 & 94,92 & 94,94 \\
\hline ADI 03 & 86,83 & 87,40 & 87,84 \\
\hline ADI 06 & 91,98 & 93,42 & 93,93 \\
\hline ADI 08 & 87,70 & 88,07 & 90,13 \\
\hline
\end{tabular}

Figura 10 - (a) Imagem ADI 01 original; (b) Imagem ADI 01 após a classificação SAM; (c) Imagem ADI 01 após a classificação por objetos; (d) Imagem ADI 01espectral somente com asfalto.

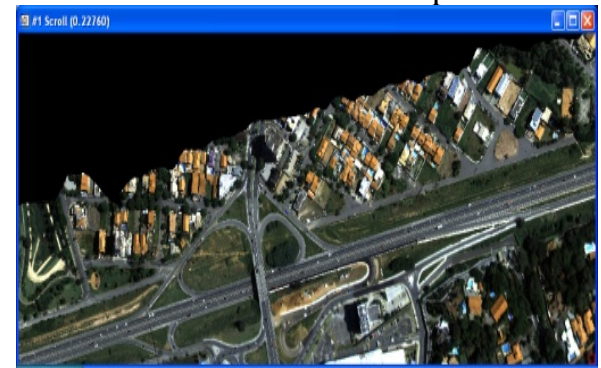

(a)

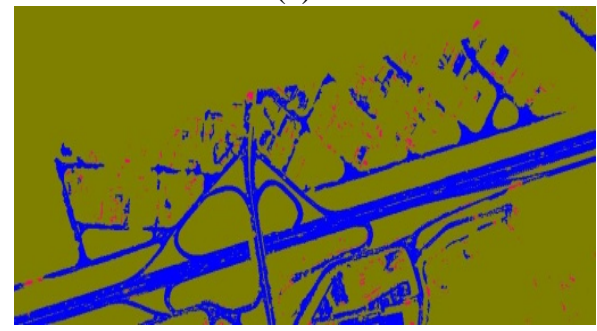

(c)

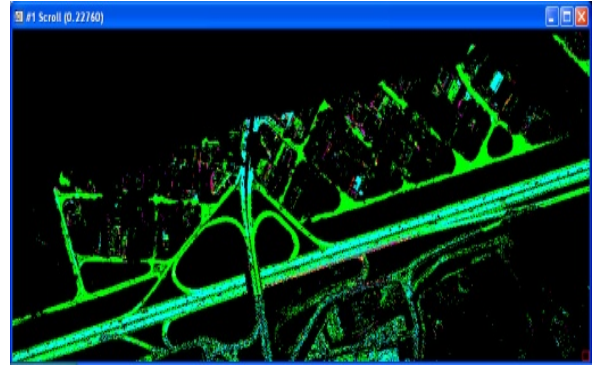

(b)

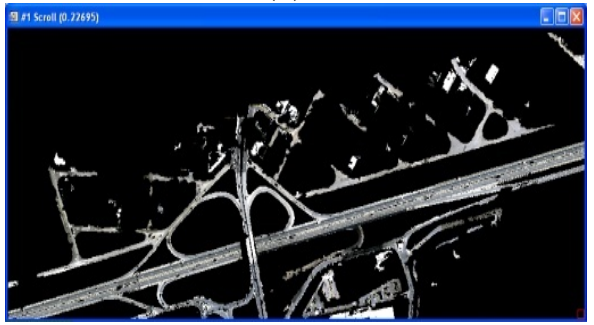

(d)

Os resultados para o segundo processo de classificação dos defeitos do asfalto são apresentados a seguir. A Tabela 3 mostra os resultados da classificação do defeito "remendo" para as quatro áreas de interesse e também para a Imagem 03. Apresenta a quantidade de objetos da imagem classificados como "remendo" e "asfalto", a área em metros quadrados equivalente dos objetos remendo e asfalto, a porcentagem dos objetos e de área de remendo em relação a quantidade de asfalto encontrado na imagem, por fim, os erros de comissão e omissão para cada ADI referentes ao objeto remendo. A classe "remendo" teve um desempenho ruim pelo classificador ao detectar remendos de asfalto nas imagens. O erro médio de 
comissão foi 55,5\% e o erro médio de omissão foi de 54\%. A contabilização da eficácia da classificação foi feita comparando visualmente a imagem classificada com a imagem original.

Tabela 3 - Resultado da classificação baseada em objetos para identificação de objetos remendos.

\begin{tabular}{l|r|r|r|r|r|r|r|r}
\hline \multirow{2}{*}{ ADI } & \multicolumn{2}{|c|}{ Nro Objetos } & \multicolumn{2}{|c|}{ Área (m2) } & \multirow{2}{*}{$\%$ Obj. } & \multirow{2}{*}{$\%$ Área } & \multirow{2}{*}{ Comissão } & \multirow{2}{*}{ Omissão } \\
\cline { 2 - 8 } & Remendo & \multicolumn{1}{|c|}{ Asfalto } & Remendo & Asfalto & & & & \\
\hline ADI-01 & 102 & 2.817 & $1.163,56$ & $60.267,31$ & $3,6 \%$ & $1,9 \%$ & $49,0 \%$ & $44,7 \%$ \\
\hline ADI-02 & 20 & 727 & 209,25 & $13.946,50$ & $2,8 \%$ & $1,5 \%$ & $55,0 \%$ & $47,1 \%$ \\
\hline ADI-03 & 12 & 906 & 97,40 & $22.034,00$ & $1,3 \%$ & $0,4 \%$ & $33,3 \%$ & $52,9 \%$ \\
\hline ADI-04 & 13 & 928 & 103,31 & $20.991,81$ & $1,4 \%$ & $0,5 \%$ & $84,6 \%$ & $71,4 \%$ \\
\hline Imagem 03 & 480 & 17.688 & $4.416,56$ & $385.856,50$ & $2,7 \%$ & $1,1 \%$ & & \\
\hline
\end{tabular}

A Tabela 4 apresenta o resultado da classificação das trincas para as duas segmentações diferentes em cada cena. Apresenta a quantidade de objetos da imagem classificados como trincas e asfalto, a área em metros quadrados equivalente dos objetos trincas e asfalto, a porcentagem dos objetos e de área de trincas em relação à quantidade de asfalto encontrado na imagem, por fim, os parâmetros utilizados na segmentação das imagens para geração dos objetos: escala, forma e compacidade (GONZALEZ; WOODS, 1992). Por não haver um método automatizado para verificação dos erros de comissão e omissão das classificações, estes não foram levantados. No entanto, o resultado qualitativo da classificação a partir da inspeção visual foi pior que a classificação dos remendos.

Tabela 4 - Resultado da classificação baseada em objetos das ADI para identificação de trincas longas.

\begin{tabular}{|c|c|c|c|c|c|c|c|c|c|}
\hline \multirow[b]{2}{*}{ ADI } & \multicolumn{2}{|c|}{ Nro Objetos } & \multicolumn{2}{|c|}{ Área (m2) } & \multirow[b]{2}{*}{$\%$ Obj. } & \multirow{2}{*}{ \% Área } & \multicolumn{3}{|c|}{ Segmentação } \\
\hline & Trinca & Asfalto & Trinca & Asfalto & & & Escala & Forma & $\begin{array}{l}\text { Compa- } \\
\text { cidade }\end{array}$ \\
\hline ADI-01 & 264 & 46.159 & 352,44 & $61.038,31$ & $0,6 \%$ & $0,6 \%$ & 20 & 0,7 & 0,9 \\
\hline ADI-01 & 109 & 20.785 & 136,44 & $61.254,81$ & $0,5 \%$ & $0,2 \%$ & 50 & 0,1 & 0,9 \\
\hline $\begin{array}{l}\text { ADI-02 } \\
\text {. }\end{array}$ & 99 & 11.953 & 126,81 & $14.019,19$ & $0,8 \%$ & $0,9 \%$ & 20 & 0,7 & 0,9 \\
\hline ADI-02 & 53 & 5.373 & 66,70 & $14.079,34$ & $1,0 \%$ & $0,5 \%$ & 50 & 0,1 & 0,9 \\
\hline ADI-03 & 129 & 14.989 & 175,06 & $21.948,75$ & $0,9 \%$ & $0,8 \%$ & 20 & 0,7 & 0,9 \\
\hline ADI-03 & 54 & 6.405 & 70,50 & $22.053,38$ & $0,8 \%$ & $0,3 \%$ & 50 & 0,1 & 0,9 \\
\hline ADI-04 & 117 & 18.470 & 146,88 & $20.945,81$ & $0,6 \%$ & $0,7 \%$ & 20 & 0,7 & 0,9 \\
\hline ADI-04 & 47 & 7.600 & 59,44 & $21.032,85$ & $0,6 \%$ & $0,3 \%$ & 50 & 0,1 & 0,9 \\
\hline
\end{tabular}

A coluna "\% Área." das Tabelas 3 e 4 apresenta os valores calculados pela Equação 1, ou seja, a coluna representa o IGI' das classes remendos e trincas respectivamente para as ADI processadas.

De posse dos índices de gravidade individual dos defeitos obtidos por imagens é possível calcular o índice gravidade global para todas as ADI. Adotando-se os mesmos fatores de ponderação descritos nas normas do DNIT para o IGG, a Tabela 
5 pode ser construída. A Tabela 5 apresenta os IGI' (\% Área) calculados nas tabelas 3 e 4, os fatores de ponderação K para remendos, trincas e buracos (DNIT 006/2003 - PRO) e o IGG’ calculado pela Equação 2.

Tabela 5 - Cálculo do IGI' e do IGG’ a partir das imagens.

\begin{tabular}{l|c|c|c|c|c|c|c}
\hline ADI & $\begin{array}{c}\text { IGI' } \\
\text { Remendo }\end{array}$ & $\begin{array}{c}\text { IGI' } \\
\text { Trincas }\end{array}$ & $\begin{array}{c}\text { IGI' } \\
\text { Buracos }\end{array}$ & $\begin{array}{c}\text { K } \\
\text { Remendo }\end{array}$ & $\begin{array}{c}\text { K } \\
\text { Trincas }\end{array}$ & $\begin{array}{c}\text { K } \\
\text { Buracos }\end{array}$ & IGG' \\
\hline ADI-01 & 0,019 & 0,006 & 0 & 0,6 & 0,2 & 1 & 0,013 \\
\hline ADI-02 & 0,015 & 0,009 & 0 & 0,6 & 0,2 & 1 & 0,011 \\
\hline ADI-03 & 0,004 & 0,008 & 0 & 0,6 & 0,2 & 1 & 0,004 \\
\hline ADI-04 & 0,005 & 0,007 & 0 & 0,6 & 0,2 & 1 & 0,004 \\
\hline
\end{tabular}

\section{DISCUSSÃO}

As imagens disponíveis para a pesquisa foram as imagens descritas na Tabela 1. Alguns problemas de qualidade nas imagens foram detectados durante o processamento, tais como: ausência de linhas (Figura 11a); linhas atenuadas; saturação e interferência do sensor nas imagens. Esta última anomalia está ligada à eletrônica do sensor, ou a alguma obstrução na fenda da aeronave diminuindo a entrada de luz necessária para a captura da imagem, iminuindo assim a relação sinal ruído do sensor. Esta anomalia deixou a imagem ligeiramente fora de foco. Para a observação e medição desta anomalia foi realizada a Análise de Componente Principal (GONZALEZ; WOODS, 1992). A última componente principal revela a quantidade de ruído na imagem conforme ilustrada na Figura 11b.

Figura 11 - (a) Imagem original e (b) PC8 - oitava componente do resultado da Análise de Componentes Principais.

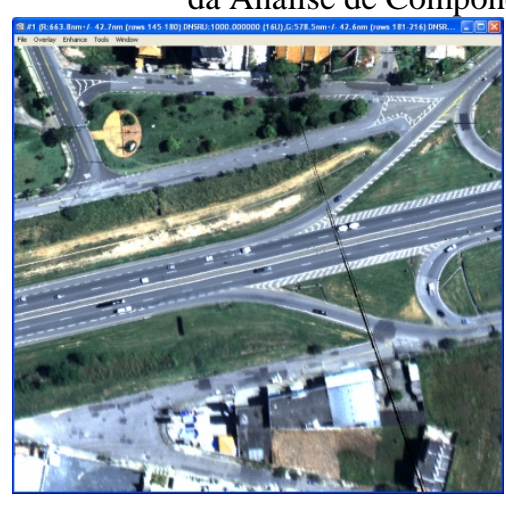

(a)

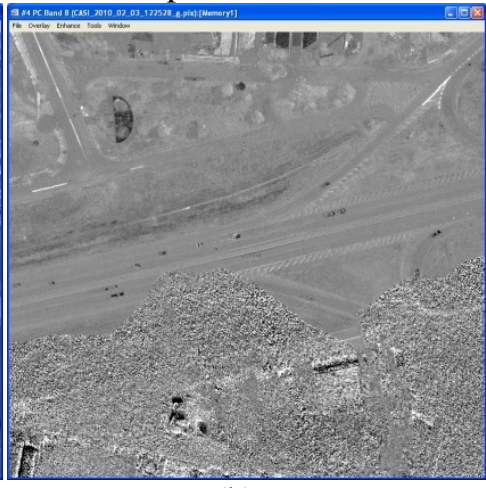

(b)

Os valores de exatidão obtidos na primeira etapa da metodologia, em torno de $90 \%$, são valores altos para resultados de classificadores supervisionados, demonstrando o excelente desempenho da etapa de detecção dos pavimentos 
asfálticos nas imagens espectrais com a metodologia apresentada. Esperava-se que as contribuições da classificação por objetos para remoção das ilhas de asfalto colaborassem mais para exatidão da classificação geral. Caso a mesma técnica seja aplicada a imagens que não sejam espectrais, a contribuição da remoção das ilhas de asfalto pode ser mais relevante. O que indica que neste caso o classificador SAM desempenhou o papel principal.

A principal vantagem na utilização dos filtros espaciais foi na atenuação do efeito do ruído eletrônico na classificação. A Tabela 6 mostra a exatidão geral antes e depois da aplicação dos filtros. Mostra ainda a porcentagem da área total da imagem ocupada pelo ruído eletrônico. O desempenho dos filtros está diretamente correlacionado com as áreas que apresentam taxa elevada de ocorrência de ruído. $\mathrm{O}$ desempenho dos filtros depende também de outros fatores, como por exemplo, se a área apresenta mais informação urbana ou rural.

Tabela 6 - Comparação da exatidão geral das áreas de interesse antes e depois da aplicação dos filtros espaciais.

\begin{tabular}{c|c|c|c|c}
\hline Área de Interesse & Exatidão SAM & $\begin{array}{c}\text { Exatidão Filtros } \\
\text { Espaciais }\end{array}$ & Diferença & $\begin{array}{c}\text { \% ruído na } \\
\text { imagem }\end{array}$ \\
\hline ADI 01 & 91,22 & 92,51 & $1,4 \%$ & $31,0 \%$ \\
\hline ADI 02 & 95,03 & 94,92 & $-0,1 \%$ & $0,0 \%$ \\
\hline ADI 03 & 86,83 & 87,40 & $0,7 \%$ & $18,0 \%$ \\
\hline ADI 06 & 91,98 & 93,42 & $1,6 \%$ & $95,0 \%$ \\
\hline ADI 08 & 87,70 & 88,07 & $0,4 \%$ & $40,0 \%$ \\
\hline
\end{tabular}

Toda segmentação das imagens foi realizada no programa Definiens 7 e vários pequenos experimentos de segmentação foram realizados com os parâmetros de escala, forma e compacidade para encontrar a melhor configuração de segmentação para os remendos, trincas e buracos do pavimento asfáltico. Para todas as segmentações realizadas nas imagens espectrais, todas as bandas das imagens receberam o mesmo peso.

A Tabela 3 apresenta os elevados erros de comissão e omissão para o classificador de objetos remendos. O desempenho ruim da classificação dos remendos, neste caso, pode estar associado a grande variabilidade de formas em que estes acontecem. O treinamento do algoritmo é feito a partir da seleção de amostras de objetos remendos e quanto maior o número de amostras melhor será o intervalo de confiança das funções de pertinência dos atributos da classe. No entanto, quanto maior o número de amostras que eram selecionadas aumentava o erro por comissão. Assim sendo, percebe-se que os atributos da classe remendo não geraram um poder discriminante forte. Ou seja, os atributos espectrais escolhidos, índice de borda, relação comprimento largura, ajuste retangular e o índice de forma não foram suficientes para gerar um classificador que fosse capaz de distinguir os objetos remendos do restante dos objetos asfalto. Além disso, a estratégia de ter uma só classe representando os remendos não mostrou desempenho aceitável. Deve ser 
investigada a possibilidade de construção de subclasses de remendos formando uma hierarquia de classe, onde cada uma destas subclasses possa ser configurada para um tipo ou grupo específico de remendo e que a soma do resultado de todas estas subclasses possam compor o índice geral de remendos.

Para o caso da classificação dos defeitos do tipo trinca, a segmentação das imagens teve uma influência maior sobre os resultados encontrados. A dimensão das trincas frente à resolução espacial das imagens foi o fator limitante para obtenção de objetos consistentes ao longo de toda a imagem e até mesmo em outras imagens semelhantes. Inicialmente, acreditava-se que a contribuição espectral durante a segmentação pudesse influenciar positivamente o segmentador aumentando sua capacidade de separar melhor as formas de interesse, mesmo em uma imagem com resolução espacial desfavorável à dimensão destes objetos. Hipótese esta que não foi comprovada com os resultados obtidos. Mesmo sem uma segmentação apropriada para a classificação dos objetos, da mesma forma que os remendos, a classe Trinca Longa deve ser reconstruída na forma de uma hierarquia de subclasses do tipo trinca, onde cada subclasse pudesse representar um tipo específico de trinca visto nas imagens. A soma de todas as subclasses representaria a classe Trinca e comporia o índice de trincas para a imagem em análise. Os resultados apresentados na Tabela 4 não são representativos da quantidade de trincas encontradas nas imagens analisadas. Servem para demonstrar que com as imagens nesta resolução espacial não é possível estabelecer uma metodologia sistemática para quantização do número de trincas e suas respectivas áreas.

\section{CONCLUSÃO}

As novas plataformas e sensores veem produzindo imagens de alta qualidade e, cada vez mais, com melhor resolução tanto espacial como espectral. A tendência da evolução tecnológica aponta para um futuro próximo em que teremos imagens com melhor resolução e com maior poder discriminante do que temos hoje.

Neste sentido, estar preparado com tecnologia e metodologias de processamento, tratamento e classificação que sejam capazes de tratar as futuras imagens de sensoriamento remoto é um desafio que pode ser trabalhado desde já.

Para a segunda fase da metodologia, a resolução espacial desempenhou papel limitante para o tipo de análise pretendida com a pesquisa, apesar das imagens possuírem alta resolução espacial para os padrões atuais de sensoriamento remoto, não foi possível classificar e segmentar de forma sistemática as imagens. A segmentação foi realizada muito próxima do nível do pixel e os objetos resultantes da segmentação não apresentaram um comportamento sistemático.

Mesmo não havendo o levantamento correto da quantidade de defeitos do pavimento asfáltico contidos nas imagens, foi possível demonstrar que a metodologia proposta e as ferramentas disponíveis permitem que sejam gerados índices de ocorrência de defeitos a partir das imagens, contabilizando a quantidade de objetos de imagens que apresentam os defeitos de superfície dos pavimentos em relação a quantidade total contida nas imagens. 
Independentemente dos resultados encontrados com o conjunto de imagens analisadas, o ponto principal do trabalho está na proposição da metodologia que utiliza as melhores técnicas existentes de classificação de imagens, misturando a classificação pixel a pixel com a classificação baseada em objetos.

Em síntese, tendo as imagens mais resolução espacial, até mesmo em detrimento da resolução espectral, é possível calcular um índice da condição do asfalto a partir de imagens. A metodologia apresentada em conjunto com novos sistemas de levantamento permitirá, no futuro próximo, o desenvolvimento de ferramentas poderosas de planejamento, acompanhamento e aferição de obras para os órgãos que administram e gerenciam as rodovias brasileiras.

\section{AGRADECIMENTOS:}

Ao Departamento de Transporte da Escola Politécnica da Universidade de São Paulo pela oportunidade e o acolhimento desta pesquisa. À Fundação Atech Tecnologias Críticas pela cessão das imagens. Ao Conselho Nacional de Pesquisa CNPq, pelo incentivo aos pesquisadores.

\section{REFERÊNCIAS BIBLIOGRÁFICAS}

AGÊNCIA NACIONAL DE TRANSPORTES TERRESTRES - ANTT. Anuário estatístico dos transportes terrestres - AETT/2008. Disponível em: $<$ http://www.antt.gov.br/ InformacoesTecnicas/aett/aett_2008/principal.asp>. Acesso em: 12 jun. 2009.

ATECH - Fundação Aplicações Tecnologias Críticas. Imagem sensor CASI 1500 da região sul da cidade de Sorocaba, SP, Brasil, 2010.

BAATZ, M.; SCHAPE, A. Multiresolution segmentation - an optimization approach for high quality multi-scale image segmentation, 2000. Disponível em: <www.ecognition.com/document>. Acesso em: 03 maio 2010.

BERNUCCI, L. B.; MOTA, L. M. G.; CERATI, J. A. P.; SOARES, J. B. Pavimentação asfáltica: formação Básica para engenheiros. Rio de Janeiro: Abeda, 2008.

BLASCHKE, T.; KUX, H. Sensoriamento remoto e SIG avançados: novos sistemas sensores métodos inovadores. São Paulo: Oficina de Textos, 2005. 286p.

BLASCHKE, T.; LANG, S.; HAY, G. J. Object-based image analysis, spatial concepts for knowledge-driven remote sensing applications. Springer, 2008.

BOARDMAN, J. W. Spectral angle mapping: a rapid measure of spectral similarity (in preparation), 1993.

DEFINIENS. Definiens Developer 7 - User Guide. Germany: Definiens AG, 2008. 506p.

DEPARTAMENTO NACIONAL DE INFRA-ESTRUTURA DE TRANSPORTES, NORMA DNIT 005/2003 - TER, Defeitos nos pavimentos flexíveis e semirígidos - Terminologia, 2003. 12p. 
DEPARTAMENTO NACIONAL DE INFRA-ESTRUTURA DE TRANSPORTES, NORMA DNIT 006/2003 - PRO, Avaliação objetiva da superfície de pavimentos flexíveis e semi-rígidos - Procedimento, 2003. 10p.

DEPARTAMENTO NACIONAL DE INFRA-ESTRUTURA DE TRANSPORTES, NORMA DNIT 007/2003 - PRO, Levantamento para avaliação da condição de superfície de subtrecho homogêneo de rodovias de pavimentos flexíveis e semirígidos para gerência de pavimentos e estudos e projetos Procedimento, 2003. 11 .

ENVI User's Guide, Research Systems Inc, 2001. 948p.

FERREIRA, E. R.; VIEIRA, C. A. O. Utilização de imagens do sensoriamento remoto para detectar defeitos nas superfícies de pavimentos asfálticos. Anais XIV Simpósio Brasileiro de Sensoriamento Remoto, Natal, Brasil, 2009(a), INPE, p. 951-958.

FERREIRA, E. R.; VIEIRA, C. A. O. Analise de curvas espectrais de 350 a 2500 nm para a discriminação de padrões de pavimentos asfálticos. Anais XIV Simpósio Brasileiro de Sensoriamento Remoto, Natal, Brasil, 2009(b), INPE, p. 1079-1086.

FUKUHARA, T.; TERADA, K.; NAGAO, M.; KASAHARA, A.; ICHIHASHI, S. Automatic pavement-distress-durvey system. In ASCE Journal of Transportation Engineering, Vol. 116, No. 3, 1990. 280-286p.

GONZALEZ, R. C.; WOODS, R. E. Digital image processing. Addison-Wesley Publishing Company Inc, 1992.

HAAS, C., SHEN, H., PHANG, W. A., HAAS, R. An expert system for automation of pavement condition inventory data, 1st North American Pavement Management Conference, 1995.

HARALICK, R. M.; SHAPIRO, L. G. Computer and robot vision. Vol. I, AddisonWeasley, Reading, 1992. 672 p.

HAY, G.J.; CASTILLA, G. Geographic object-based image analysis (GEOBIA). In: Blaschke T, Lang S, Hay GJ (eds) object-based image analysis - spatial concepts for knowledge-driven remote sensing applications. Berlin: SpringerVerlag, 2008.

HEROLD, M.; ROBERTS, D.; NORONHA, V.; SMADI, O. Imaging spectrometry and asphalt road surveys. Transportation Research Part C 16, 2008. 153-166p.

LANG, S. Object-based image analysis for remote sensing applications: modeling reality - dealing with complexity, Springer Berlin Heidelberg , 2008. 3-27p.

LILLESAND, T.M. ; KIEFER, R.W.; CHIPMAN, J. W. Remote sensing and image interpretation. 6th Edition. John Wiley \& Sons, 2007. 756p.

LU, D.; WENG, Q. A survey of image classification methods and techniques for improving classification performance, International journal of Remote sensing, 2007.

NAVULUR, K. Multispectral image analysis using the object-oriented paradigm. Boca Raton: Taylor \& Francis Group, 2006. 165p. 
NEUBERT, M.; HEROLD, H.; MEINEL, G. Evaluation of remote sensing image segmentation quality - further results and concepts, 2006.

NOBREGA, R. A. A. ; OHARA, C. G. ; QUINTANILHA, J. A. An object-based approach to mine roads over informal settlements in Sao Paulo city. In: Blaschke, T., Lang, S., Hay, G. (eds.). (Org.). Object based image analysis. Berlin: Springer, Heidelberg, Berlin, New York, 2008. 595-613p.

PINHEIRO, E. S.; KUX, H. J. H. Imagens Quickbird Aplicadas ao mapeamento do uso e cobertura da terra do centro de pesquisas e conservação da natureza prómata. In Sensoriamento Remoto e SIG: Novos Sistemas e Sensores: Métodos Inovadores. São Paulo, Oficina de Textos, 2005. 286p.

RESENDE, M. R. Investigação do uso de imagens de sensor de sensoriamento remoto hiperespectral e com alta resolução espacial no monitoramento da condição de uso de pavimentos rodoviários. 130p. Dissertação. São Paulo, 2010.

RESENDE, M. R.; BERNUCCI, L.L.B.; QUINTANILHA, J. A. Monitoring the condition of roads pavement surfaces: proposal of methodology using hyperspectral images with high spatial resolution - submetido ao International Journal of Pavements, 2012.

RESENDE, M. R.; JORGE, S. C. H.; LONGHITANO, G. A.; QUINTANILHA, J. A. Use of hyperspectral and high spatial resolution image data in an asphalted urban road extraction. IEEE International Geoscience \& Remote Sensing Symposium - IGARSS2008, 2008, Boston, Massachusetts, U.S.A.. Proceedings of IGARSS2008, 2008.

RODRIGUES, L. M.; RESENDE, M. R.; TIMOSZCZUK, A. P. Sistema de imageamento hiperespectral de alta resolução embarcado em plataforma aérea de baixo custo, XIII Simpósio Brasileiro de Sensoriamento Remoto - SBSR, Florianópolis - SC, 2007.

WANG, K. C. P. SMADI, O. Automated imaging technologies for pavement distress surveys, Transportation Research Circular E-C156, 2011.

(Recebido em março de 2012. Aceito em julho de 2012.) 